\title{
PENINGKATAN KUALITAS KNALPOT PADA PT FAJAR INDAH MENGGUNAKAN METODE SIX SIGMA
}

\author{
LAURENTIUS DANNY DHARMAWAN DAN YURIDA EKAWATI \\ Program Studi Teknik Industri, Universitas Ma Chung Malang \\ Jl. Villa Puncak Tidak N-01, Malang 65651 \\ Surel: laurentiusdanny@gmail.com,yurida.ekawati@machung.ac.id
}

\begin{abstract}
ABSTRAK
PT Fajar Indah adalah perusahaan yang bergerak pada bidang otomotif dimana salah satu produk andalannya adalah knalpot Colt Diesel FE 120 PS. Selama tahun 2012 dan 2013 PT Fajar Indah mampu memproduksi hingga 2400 unit knalpot dengan tingkat defect sebesar 6-7\%. Terdapat lima jenis kecacatan yang memengaruhi kualitas dari produk knalpot ini, yaitu defect kip tutup, defect pada ring, defect ukuran sarangan, defect ukuran potong plat, dan defect plat pecah. Untuk mengetahui apakah pada proses produksi knalpot ini perlu dilakukan perbaikan dan bagaimana caranya maka dilakukan analisis six sigma. Analisis dilakukan melalui proses DMAIC dimana untuk penentuan usulan perbaikan melalui analisis RCA dan FMEA. Berdasarkan hasil analisis didapatkan bahwa PT Fajar Indah memiliki nilai DPMO dan sigma sebesar 12.879 dan 3,73 yang menunjukkan bahwa perbaikan masih perlu dilakukan pada proses produksi knalpot. Usulan perbaikan yang dapat dilakukan antara lain adalah menyusun jadwal maintenance, menyusun work instruction serta melakukan pengawasan, perbaikan cara penyimpanan cetakan ring, menyediakan tempat khusus untuk plat sisa hasil pemotongan, menambah jumlah pekerja untuk bagian inspeksi, dan mencari supplier yang mampu menyediakan plat dengan kualitas yang standar.
\end{abstract}

Kata kunci: knalpot, defect, six sigma, DMAIC, FMEA

\begin{abstract}
PT Fajar Indah is an automotive company which is one of their flagship products is muffler for Colt Diesel FE 120 PS. During 2012 and 2013, PT Fajar Indah was able to produced muffler up to 2400 unit with 6-7\% defects rate. There are five type of defects that affects muffler's quality which are lid's defects, ring's defects, defects of resonator's size, defects of plate's cutting size, and defects of broken plate. To determine whether improvements are needed in muffler's prodution process and how they will be conducted so six sigma will be used for analysis. Analysis was conducted using DMAIC process, where recommended action for quality improvement were determined with RCA and FMEA. Result from analysis shows that PT Fajar Indah had 12,879 DPMO value and 3.73 sigma which mean that improvement is needed in muffler's production process. Some recommended actions that can be done are maintenance scheduling, making work instruction and supervise it, improving storage method for ring's model, provide place for plate scraps from cutting process, adding more workesr for products inspection, and looking for suppliers who are able to provide plate with standard quality.
\end{abstract}

Key words: muffler, defect, six sigma, DMAIC, FMEA

\section{PENDAHULUAN}

Industri otomotif adalah salah satu bidang industri yang dituntut mampu menghasilkan produk berkualitas tinggi, salah satunya adalah PT Fajar Indah. Knalpot mobil dan sepeda motor merupakan produk utama dari PT Fajar Indah. Selain knalpot mobil dan sepeda motor, PT Fajar Indah juga memproduksi knalpot/sistem pembuangan untuk alat pembangkit listrik serta aksesoris otomotif lainnya. Produk yang 
dihasilkan oleh PT Fajar Indah saat ini hanya dipasarkan di dalam negeri. PT Fajar Indah telah menjadi produsen knalpot mobil nomor satu di Indonesia dan sedang berusaha untuk menjadi produsen knalpot motor nomor satu pula.

Salah satu produk yang menjadi andalan dari PT Fajar Indah adalah knalpot untuk Colt Diesel FE 120 PS. Knalpot Colt Diesel FE 120 PS ini memiliki target produksi sebesar 2400 unit per bulan. Dari data produksi pada Tabel 1, diketahui bahwa dalam proses produksi knalpot Colt Diesel FE 120 PS memiliki jumlah produk defect yang dirasa masih cukup besar dimana memiliki persentase antara 6-7\% dalam produksi aktualnya. Perusahaan sendiri menginginkan produk yang defect berada pada kisaran $5 \%$. Oleh karena itu perusahaan menginginkan adanya perbaikan pada proses produksi knalpot Colt Diesel FE 120 PS untuk dapat memenuhi target tersebut.

Perbaikan kualitas di perusahaan dapat dilakukan dengan menggunakan metode Six Sigma yang merupakan suatu filosofi untuk mengurangi variasi pada seluruh proses kritis untuk mendapatkan perbaikan yang bersifat terobosan dan terus-menerus (Chakrabortty dkk., 2013). Perbaikan pada proses bertujuan untuk menghasilkan perbaikan pada hasil (Ray dan John, 2011). Tujuan dari penelitian ini adalah untuk mengurangi variasi pada produksi knalpot dengan menurunkan tingkat cacat pada produk tersebut. Penurunan tingkat cacat menggunakan metode Six Sigma berdasar siklus DMAIC (Define-Measure-Analyze-Improve-Control) (Nee dkk., 2012).

\section{METODE}

Terdapat empat tahapan proses yang dilaksanakan dalam penelitian ini, yaitu define, measure, analyze, dan improve. Tahap control tidak dilaksanakan karena hasil dari penelitian bersifat usulan. Beberapa kombinasi alat bantu analisis kualitas dapat diterapkan pada setiap tahap DMAIC (Julien dan Holmshaw, 2012). Pada tahapan define dilakukan penentuan sasaran dan tujuan perbaikan serta identifikasi defect atau kecacatan produk yang terjadi (Dewi, 2012).

Proses kedua adalah measure dimana pada tahapan ini akan dilakukan identifikasi terhadap waste yang paling berpengaruh pada peningkatan kualitas produk, pengidentifikasian CTQ (Critical To Quality) yaitu atribut-atribut dari produk yang diinginkan oleh pihak konsumen (Vanany dan Emilasari, 2007) melalui diagram pareto, dan melakukan pengukuran kapabilitas proses dan nilai DPMO serta sigma. Melalui nilai indeks kapabilitas proses $\left(\mathrm{C}_{\mathrm{p}}\right)$ maka dapat dilihat bagaimana keadaan proses industri pada perusahaan (Mentari, 2011), yaitu sebagai berikut nilai $\mathrm{C}_{\mathrm{p}} \geq 2,0$ menunjukkan bahwa proses

Tabel 1. Data Produksi Knalpot Colt Diesel FE 120 PS Tahun 2012

\begin{tabular}{lcccc}
\hline \multicolumn{1}{c}{ Bulan } & Target Produksi & Produksi Aktual & Defect & \%Defect \\
\hline Januari & 2400 & 2330 & 172 & $7,38 \%$ \\
Februari & 2400 & 2159 & 146 & $6,76 \%$ \\
Maret & 2400 & 2368 & 149 & $6,29 \%$ \\
April & 2400 & 2355 & 155 & $6,58 \%$ \\
Mei & 2400 & 2273 & 173 & $7,61 \%$ \\
Juni & 2400 & 2354 & 171 & $7,26 \%$ \\
Juli & 2400 & 2320 & 141 & $6,08 \%$ \\
Agustus & 1200 & 1202 & 85 & $7,07 \%$ \\
September & 2400 & 2245 & 173 & $7,71 \%$ \\
Oktober & 2400 & 2423 & 172 & $7,10 \%$ \\
November & 2400 & 2375 & 180 & $7,58 \%$ \\
Desember & 2400 & 2409 & 176 & $7,31 \%$ \\
\hline
\end{tabular}


Tabel 2. Kategori Perusahaan Berdasarkan Nilai DPMO dan Sigma

\begin{tabular}{lcc}
\hline Kategori & DPMO & Nilai Sigma \\
\hline Perusahaan sangat tidak kompetitif dimana kualitas produk & 691.462 & 1 \\
yang dihasilkan tidak bagus. & 308.538 & 2 \\
Rata-rata industri/perusahaan di Indonesia & 66.807 & 3 \\
Perusahaan yang sedang berkembang dan dapat bersaing & 6.210 & 4 \\
dengan perusahaan lainnya & 233 & 5 \\
Rata-rata industri/perusahaan di Amerika & 3,4 & 6 \\
berkuahaan besar yang mampu menghasilkan produk yang & & \\
Industri/perusahaan kelas dunia & & \\
\hline
\end{tabular}

industri berada dalam keadaan yang stabil dan mampu menghasilkan produk yang sesuai dengan kebutuhan konsumen. Apabila $1 \leq \mathrm{C}_{\mathrm{p}} \leq 1,99$ maka proses industri berada dalam keadaan yang stabil namun masih belum mampu menghasilkan produk yang sesuai dengan kebutuhan dan keinginan konsumen, sedangkan apabila $\mathrm{C}_{\mathrm{p}}<$ 1,0 berarti bahwa proses industri tidak mampu untuk menghasilkan produk yang sesuai dengan kebutuhan dan keinginan konsumen.

Nilai DPMO dan sigma dihitung menggunakan bantuan software SPC Wizard's Sigma Calculator. Nantinya nilai DPMO dan sigma ini akan memperlihatkan kategori dimana perusahaan berada seperti yang ditunjukkan oleh Tabel 2 (Gaspersz, 2007).

Proses selanjutnya adalah analyze dimana pada proses ini dilakukan analisis terhadap data yang telah diperoleh untuk mencari dan menemukan faktor-faktor penyebab terjadinya suatu masalah yang dalam penelitian ini adalah faktor-faktor penyebab terjadinya defect. Untuk menganalisis faktor penyebab digunakan RCA (Root Cause Analysis). Dalam menyusun sebuah RCA, hal pertama yang dilakukan adalah merumuskan masalah yang akan dicari akar penyebabnya (Harsono, 2008). Setelah itu dilakukan identifikasi sebab-sebab negatif langsung dari masalah tersebut. Sebab-sebab langsung ini selanjutnya akan dianalisis kembali untuk mencari penyebabnya. Tahap pencarian penyebab dari suatu sebab langsung ini akan terus dilakukan sampai dengan ditemukan penyebab utamanya.
Proses terakhir adalah improve dimana pada proses ini menentukan tindakan atau usulanusulan perbaikan terhadap proses produksi untuk meminimalkan waste dan defect berdasarkan hasil analisis yang telah dilakukan sebelumnya (Ardita dan Sukardi, 2012). Tahap improve ini dilakukan dengan menggunakan analisis FMEA (Failure Mode and Effect Analysis) yang bertujuan untuk mengidentifikasi dan mengevaluasi tingkat kegagalan (failure) potensial yang ada pada suatu sistem, produk atau proses yang memengaruhi produk atau proses (Riandiani, 2010). Terdapat tiga langkah yang harus dijalankan dalam proses analisis FMEA, yaitu menganalisis potential effect dari failure mode, menganalisis potential causes dari failure mode, dan menganalisis control method dari failure mode (Burlikowska, 2011). Setelah melakukan ketiga langkah diatas maka dapat dilakukan penyusunan recommeded action atau usulan perbaikan. Dalam FMEA ini akan ditentukan nilai severity $(\mathrm{S})$, occurrence $(\mathrm{O})$, serta detection (D) yang nantinya akan digunakan untuk menentukan nilai RPN ( Risk Priority Number). Nilai RPN yang didapatkan dari hasil perkalian nilai severity, occurrence, dan detection ini menunjukkan skala prioritas terhadap risiko kualitas yang dilakukan dalam pelaksanaan action plan. Nilai RPN terbesar akan menjadi prioritas utama yang akan dilakukan perbaikan terlebih dahulu oleh perusahaan. Tahap terakhir dari penelitian adalah tahapan pengambilan kesimpulan dari hasil penelitian yang telah dilakukan dan saran bagi perusahaan. 


\section{HASIL DAN PEMBAHASAN}

Terdapat lima jenis defect yang terjadi pada proses produksi knalpot Colt Diesel FE 120 PS pada tahun 2013 yang dapat dilihat pada Tabel 3, yaitu defect ring, defect kip tutup, defect ukuran potong, plat pecah, dan defect ukuran sarangan. Setelah diketahui cacat pada proses produksi knalpot maka dapat dilakukan proses pengukuran prioritas pada jenis cacat yang terjadi (CTQ) dengan menggunakan diagram pareto. Diagram pareto pada Gambar 1 menunjukkan bahwa CTQ (Critical to Quality)/cacat produk yang menjadi prioritas utama perusahaan untuk diperbaiki adalah defect kip tutup.

Selanjutnya dilakukan perhitungan nilai DPMO dan sigma untuk mengetahui pada kategori mana PT Fajar Indah berada pada saat ini. Berdasarkan pada Tabel 4 maka dapat disimpulkan bahwa dengan nilai DPMO dan nilai sigma pada tahun 2013 sebesar 12.879 dan 3,73 maka PT Fajar Indah termasuk dalam kategori perusahaan yang sedang berkembang dan memiliki kemampuan untuk bersaing dengan para perusahaan kompetitor.

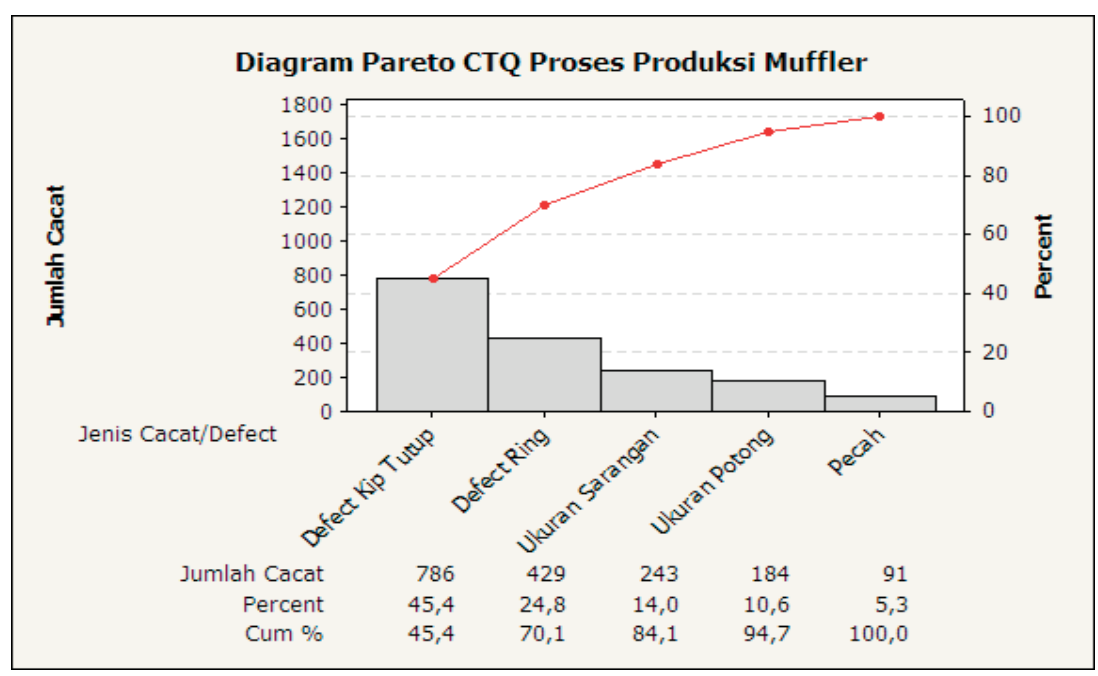

Gambar 1. Diagram Pareto CTQ pada Proses Produksi Knalpot (Muffer)

Tabel 3. Data Jenis Cacat Produk Knalpot Colt Diesel FE 120 PS Tahun 2013

\begin{tabular}{|c|c|c|c|c|c|c|}
\hline \multirow[b]{2}{*}{ Bulan } & \multicolumn{5}{|c|}{ Jenis Defect } & \multirow[b]{2}{*}{ Total } \\
\hline & Defect Ring & $\begin{array}{c}\text { Defect Kip } \\
\text { Tutup }\end{array}$ & $\begin{array}{l}\text { Ukuran } \\
\text { Potong }\end{array}$ & Pecah & $\begin{array}{c}\text { Ukuran } \\
\text { Sarangan }\end{array}$ & \\
\hline Januari & 32 & 75 & 18 & 2 & 19 & 146 \\
\hline Februari & 33 & 52 & 20 & 7 & 30 & 142 \\
\hline Maret & 46 & 83 & 10 & 3 & 18 & 160 \\
\hline April & 33 & 56 & 14 & 9 & 27 & 139 \\
\hline Mei & 40 & 54 & 22 & 15 & 20 & 151 \\
\hline Juni & 44 & 78 & 12 & 12 & 16 & 162 \\
\hline Juli & 33 & 73 & 14 & 12 & 17 & 149 \\
\hline Agustus & 16 & 40 & 9 & 6 & 7 & 78 \\
\hline September & 37 & 67 & 15 & 1 & 25 & 145 \\
\hline Oktober & 40 & 62 & 21 & 15 & 23 & 161 \\
\hline November & 36 & 74 & 16 & 3 & 24 & 153 \\
\hline Desember & 39 & 72 & 13 & 6 & 17 & 147 \\
\hline Total & 429 & 786 & 184 & 91 & 243 & 1733 \\
\hline
\end{tabular}


Tabel 4. Hasil Perhitungan Nilai DPMO dan Sigma

\begin{tabular}{lcccc}
\hline \multicolumn{1}{c}{ Bulan } & Total Produksi & $\begin{array}{c}\text { Total Produk } \\
\text { Defect }\end{array}$ & DPMO & Sigma \\
\hline Januari & 2337 & 146 & 12.495 & 3,74 \\
Februari & 2352 & 142 & 12.075 & 3,75 \\
Maret & 2295 & 160 & 13.943 & 3,7 \\
April & 2304 & 139 & 12.066 & 3,76 \\
Mei & 2345 & 151 & 12.878 & 3,73 \\
Juni & 2324 & 162 & 13.941 & 3,7 \\
Juli & 2354 & 149 & 12.659 & 3,74 \\
Agustus & 1207 & 78 & 12.925 & 3,73 \\
September & 2325 & 145 & 12.473 & 3,74 \\
Oktober & 2353 & 161 & 13.685 & 3,71 \\
November & 2348 & 153 & 13.032 & 3,73 \\
Desember & 2367 & 147 & 12.421 & 3,74 \\
Tahun 2013 & 26911 & 1733 & 12.879 & 3,73 \\
\hline
\end{tabular}

Kemampuan perusahaan dalam memproduksi produk yang sesuai dengan kebutuhan konsumen akan diukur dengan perhitungan kapabilitas proses. Perhitungan kapabilitas proses ini akan dilakukan dengan bantuan software Minitab 16. Perhitungan yang akan digunakan adalah Binomial Capability Analysis dikarenakan jenis datanya adalah data atribut sehingga harus berdasarkan pada distribusi discrete distribution.

Berdasarkan hasil analisis kapabilitas proses pada Gambar 2 didapatkan nilai Process Z dari proses produksi knalpot Colt Diesel FE 120 PS adalah sebesar 1,5189. Dimana semakin besar nilai dari Process Z maka menunjukkan bahwa semakin baik pula proses produksi produk tersebut. Apabila proses produksi telah mencapai Six Sigma maka Process Z akan bernilai 4,5. Sedangkan untuk nilai $\mathrm{Cp}$ dari proses produksi knalpot Colt Diesel FE 120 PS dilakukan dengan menggunakan cara mengkonversikan nilai DPMO yang telah didapatkan sebelumnya ke dalam nilai Cp. Pada tahun 2013 diperoleh nilai DPMO sebesar 12.879 maka setelah dilakukan konversi didapatkan bahwa nilai $\mathrm{Cp}$ proses produksi knalpot Colt Diesel FE 120 PS adalah sebesar 1,243 . Perusahaan biasanya menggunakan nilai Cp sebesar 1,33 sebagai benchmark value. Karena nilai $\mathrm{Cp}$ proses produksi knalpot Colt Diesel FE 120 PS yang masih lebih kecil dari benchmark value maka diperlukan perbaikan pada proses produksi.

Seperti yang telah diketahui sebelumnya bahwa selama proses produksi knalpot Colt Diesel FE 120 PS terdapat lima jenis cacat/defect (CTQ), yaitu defect kip tutup, defect ring, ukuran sarangan, ukuran potong, dan yang terakhir adalah pecah. Karena telah diketahui CTQ apa saja yang memengaruhi proses produksi maka selanjutnya dilakukan analisis untuk mengetahui penyebab dari munculnya jenis cacat/defect (CTQ) tersebut. Proses analisis akan dilakukan dengan menggunakan RCA (Root Cause Analysis). Berikut ini adalah analisis melalui RCA untuk masing-masing CTQ:

1. Defect Kip Tutup

Defect kip tutup yang terjadi adalah tutup knalpot yang tidak rapat dikarenakan oleh proses kip oleh mesin kip kurang maksimal dan kip tutup hasil proses las kurang rapi. Setelah dilakukan analisis RCA yang dapat dilihat pada Tabel 5, diketahui bahwa penyebab utama terjadinya defect kip tutup adalah tidak adanya jadwal maintenance mesin kip, operator mesin potong kurang teliti saat memotong plat, dan operator las kurang cermat saat melakukan las.

2. Defect Ring

Defect ring yang terjadi adalah knalpot tidak dapat dirakit karena posisi lubang ring ataupun ukuran ring yang digunakan 


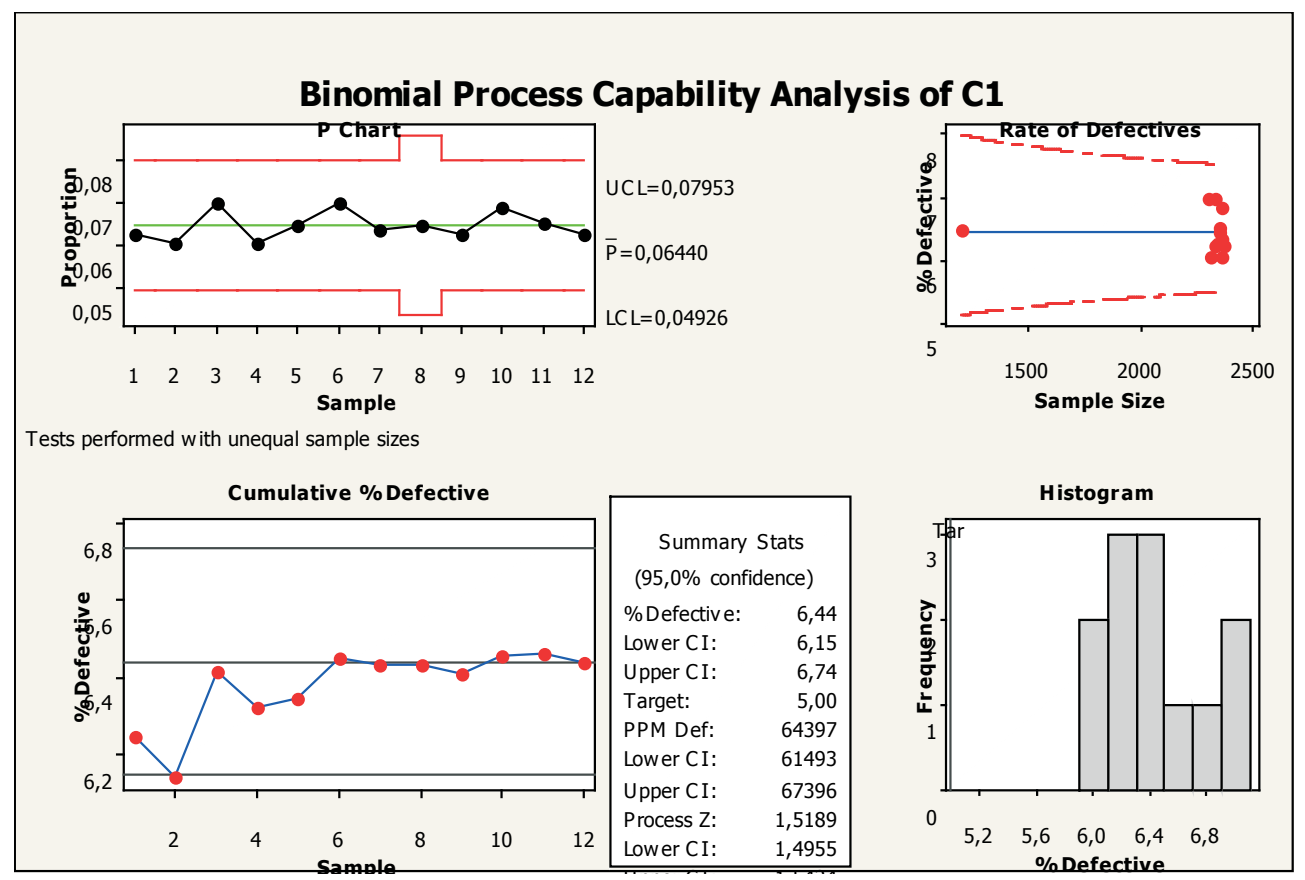

Gambar 2. Hasil Analisis Kapabilitas Proses Knalpot Colt Diesel FE 120 PS

Tabel 5. RCA Defect pada Kip Tutup

\section{Sebab a1}

Mesin Kip tidak mampu

melakukan proses kip dengan

rapat

Sebab a2.1

Rol pada mesin bubut sudah mengalami keausan

\section{Sebab a3.1}

Tidak ada jadwal maintenance untuk mengganti/membubut rol

Tabel 6. RCA Defect pada Ring

\begin{tabular}{lll}
\hline Sebab a1 & Sebab b1 & Sebab c1 \\
Posisi lubang ring yang tidak & Ukuran ring yang dicetak tidak & Operator kurang teliti saat \\
sesuai dengan standar & sesuai dengan standar & melakukan inspeksi produk \\
Sebab a2 & Sebab b2 & Sebab c2 \\
$\begin{array}{l}\text { Cetakan/model yang digunakan } \\
\text { tidak sesuai dengan yang }\end{array}$ & Cetakan/model yang digunakan & Operator tidak teliti karena \\
semestinya & tidak sesuai dengan yang semestinya & waktu kerja yang terbatas dan \\
Sebab a3 & Sebab b3 & Sebab c3 \\
Operator salah met produksi \\
cetakan/model & Operator salah mengambil cetakan/ & Tidak ada pekerja yang \\
Sebab a4 & model & khusus melakukan inspeksi \\
Tempat disimpannya tidak & Sebab b4 & \\
tertata dengan rapi & Tempat disimpannya tidak tertata & \\
\hline
\end{tabular}

\section{Sebab a2.2}

Potongan plat yang akan dilakukan proses Kip tutup tidak melakukan las rata

\section{Sebab a3.2}

Operator mesin potong kurang

\section{Sebab b2}

\section{Sebab b1}

Kip tutup dari hasil las kurang rapi sehingga kip tutup tidak tertutup dengan rapat

Operator las kurang cermat saat

teliti saat memotong plat 
Tabel 7. RCA Defect pada Ukuran Sarangan

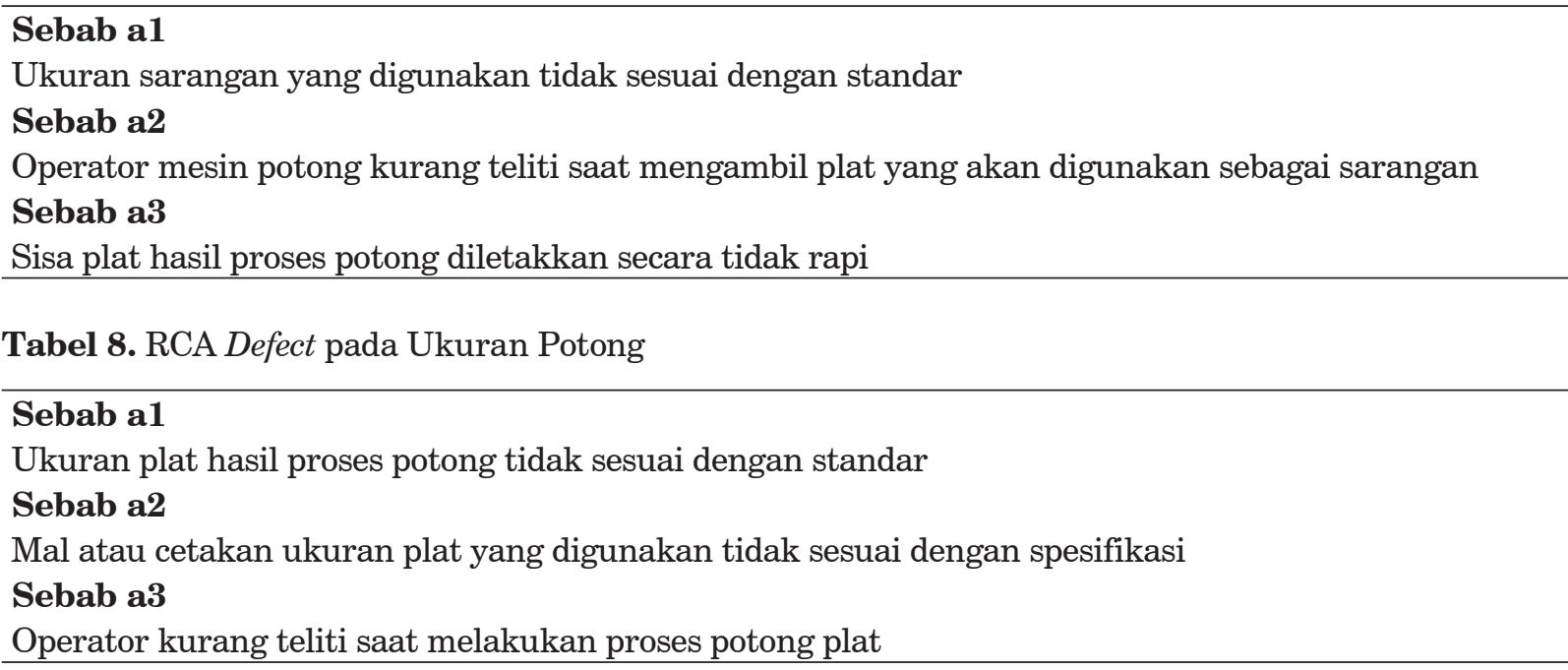

Tabel 9. RCA Defect Akibat Plat Pecah

\begin{tabular}{l} 
Sebab a1 \\
Bahan baku plat yang digunakan terlalu keras dan tidak sesuai standar \\
Sebab a2 \\
Bahan baku plat yang tersedia kualitasnya tidak sama merata \\
Sebab a3 \\
Perusahaan mencari harga plat yang murah sehingga plat yang didapatkan tidak berkualitas standar \\
\hline
\end{tabular}

ternyata tidak sesuai dengan spesifikasi yang telah ditentukan. Defect ring sendiri disebabkan oleh posisi lubang ring yang tidak sesuai standar, ukuran ring yang tidak sesuai standar, dan proses inspeksi yang kurang teliti yang menyebabkan lolosnya produk defect. Berdasarkah hasil RCA pada Tabel 6, didapatkan bahwa penyebabpenyebab utama terjadinya defect ring adalah tempat penyimpanan cetakan/model dari ring yang belum tersimpan dengan rapi dan perusahaan tidak memiliki pekerja yang khusus menangani proses inspeksi.

3. Defect pada Ukuran Sarangan

Berdasarkan hasil RCA pada Tabel 7, defect pada bagian sarangan atau resonator pada knalpot yang terjadi adalah ukuran sarangan yang digunakan lebih kecil dan tipis daripada spesifikasi yang ditentukan, dimana hal tersebut akan memengaruhi kualitas pembuangan dan kualitas suara yang dihasilkan. Defect yang terjadi pada bagian sarangan knalpot adalah ukuran ketebalan sarangan yang digunakan tidak sesuai dengan standar. Hal tersebut disebabkan karena bahan baku sarangan yaitu plat sisa proses potong tidak diletakkan dengan rapi melainkan hanya ditumpuk menjadi satu bagian sehingga pekerja kesulitan untuk memilih ketebalan plat yang akan digunakan.

4. Defect Ukuran Potong

Defect karena ukuran potong yang terjadi pada proses produksi ini menyebabkan plat yang tidak berukuran standar tersebut tidak dapat digunakan untuk proses produksi selanjutnya. Hasil RCA pada Tabel 8 memperlihatkan defect ukuran potong terjadi akibat ukuran potong plat tidak sesuai dengan standar. Dimana hal tersebut disebabkan akibat kesalahan operator yang kurang teliti saat menggunakan mal atau cetakan plat.

5. Defect Akibat Plat Pecah

Dalam proses produksi terkadang ditemui adanya plat yang pecah pada proses pencetakan tutup knalpot. Berdasarkan Tabel 9, plat yang mengalami pecah ini disebabkan oleh kualitas dari bahan baku plat yang digunakan perusahaan terlalu keras dan tidak 
sesuai dengan standar. Hal ini disebabkan karena pihak perusahaan yang mencari bahan baku plat dengan harga yang murah namun tidak diimbangi dengan kualitas yang memuaskan.

Setelah faktor-faktor penyebab terjadinya cacat/defect pada proses produksi knalpot Colt Diesel FE 120 PS diketahui maka selanjutnya adalah menentukan usulan perbaikan yang akan dilakukan dengan menggunakan FMEA. FMEA ini bertujuan untuk menentukan CTQ atau jenis cacat/defect yang menjadi prioritas perusahaan untuk dilakukan perbaikan terlebih dahulu. Prioritas perbaikan yang akan dilakukan pada FMEA ini ditandai melalui nilai Risk Priority Number (RPN).

Berdasarkan hasil FMEA pada Tabel 10, diketahui bahwa potential failure yang menjadi

Tabel 10. Hasil FMEA pada Proses Produksi Knalpot Colt Diesel FE 120 PS

\begin{tabular}{|c|c|c|c|c|c|c|c|c|}
\hline $\begin{array}{l}\text { Process } \\
\text { Function }\end{array}$ & $\begin{array}{l}\text { Potential } \\
\text { Failure }\end{array}$ & $\begin{array}{l}\text { Potential } \\
\text { Effects of } \\
\text { Failure }\end{array}$ & Severity & $\begin{array}{l}\text { Potential } \\
\text { Causes }\end{array}$ & Occurance & $\begin{array}{l}\text { Current } \\
\text { Process } \\
\text { Control }\end{array}$ & Detection & RPN \\
\hline \multirow[t]{4}{*}{ Knalpot } & $\begin{array}{l}\text { Defect kip } \\
\text { tutup }\end{array}$ & Rework & 7 & $\begin{array}{l}\text { Tidak ada jadwal } \\
\text { maintenance } \\
\text { untuk mengganti/ } \\
\text { membubut rol }\end{array}$ & 10 & Visual & 4 & 280 \\
\hline & & & & $\begin{array}{l}\text { Operator mesin } \\
\text { potong kurang } \\
\text { teliti saat } \\
\text { memotong plat }\end{array}$ & 3 & Visual & 4 & 84 \\
\hline & & & & $\begin{array}{l}\text { Operator las } \\
\text { kurang cermat } \\
\text { saat melakukan } \\
\text { las }\end{array}$ & 4 & Visual & 4 & 112 \\
\hline & $\begin{array}{l}\text { Ukuran } \\
\text { potong }\end{array}$ & $\begin{array}{l}\text { Plat tidak } \\
\text { dapat } \\
\text { digunakan }\end{array}$ & 4 & $\begin{array}{l}\text { Operator kurang } \\
\text { teliti saat } \\
\text { melakukan proses } \\
\text { potong plat }\end{array}$ & 6 & Visual & 7 & 168 \\
\hline \multirow[t]{2}{*}{ Ring } & $\begin{array}{l}\text { Defect } \\
\text { ring }\end{array}$ & $\begin{array}{l}\text { Proses } \\
\text { assembly } \\
\text { tidak dapat } \\
\text { dilakukan }\end{array}$ & 8 & $\begin{array}{l}\text { Tempat } \\
\text { disimpannya tidak } \\
\text { tertata dengan } \\
\text { rapi }\end{array}$ & 6 & Visual & 5 & 240 \\
\hline & & & & $\begin{array}{l}\text { Tidak ada pekerja } \\
\text { yang khusus } \\
\text { membidangi QC } \\
\text { dan melakukan } \\
\text { inspeksi }\end{array}$ & 8 & Visual & 5 & 64 \\
\hline Tutup & Plat pecah & $\begin{array}{l}\text { Tutup akan } \\
\text { pecah saat } \\
\text { dilakukan } \\
\text { proses } \\
\text { potong dan } \\
\text { kip tutup }\end{array}$ & 8 & $\begin{array}{l}\text { Perusahaan } \\
\text { mencari harga } \\
\text { plat yang murah } \\
\text { sehingga plat } \\
\text { yang didapatkan } \\
\text { tidak berkualitas } \\
\text { standar }\end{array}$ & 5 & Visual & 3 & 120 \\
\hline Sarangan & $\begin{array}{l}\text { Ukuran } \\
\text { sarangan }\end{array}$ & $\begin{array}{l}\text { Suara yang } \\
\text { dihasilkan } \\
\text { knalpot } \\
\text { menjadi } \\
\text { kasar }\end{array}$ & 4 & $\begin{array}{l}\text { Sisa plat hasil } \\
\text { proses potong } \\
\text { diletakkan secara } \\
\text { tidak rapi }\end{array}$ & 7 & Caliper & 4 & 112 \\
\hline
\end{tabular}


Tabel 11. Usulan Perbaikan untuk PT Fajar Indah Berdasarkan Hasil FMEA

\begin{tabular}{|c|c|c|c|c|}
\hline $\begin{array}{l}\text { Potential } \\
\text { Failure }\end{array}$ & $\begin{array}{l}\text { Potential } \\
\text { Effects of } \\
\text { Failure }\end{array}$ & Potential Causes & $\mathbf{R P N}$ & Recommended Actions \\
\hline \multirow[t]{3}{*}{$\begin{array}{l}\text { Defect kip } \\
\text { tutup }\end{array}$} & Rework & $\begin{array}{l}\text { Tidak ada jadwal } \\
\text { maintenance untuk } \\
\text { mengganti/membubut rol }\end{array}$ & 280 & $\begin{array}{l}\text { Melakukan penjadwalan } \\
\text { maintenance untuk } \\
\text { mengganti rol maupun untuk } \\
\text { membubut rol mesin kip } \\
\text { tutup }\end{array}$ \\
\hline & & $\begin{array}{l}\text { Operator mesin potong } \\
\text { kurang teliti saat memotong } \\
\text { plat }\end{array}$ & 84 & $\begin{array}{l}\text { Menyusun work instruction } \\
\text { agar pekerja dapat bekerja } \\
\text { dengan lebih terorganisir dan } \\
\text { melakukan pengawasan yang } \\
\text { lebih ketat }\end{array}$ \\
\hline & & $\begin{array}{l}\text { Operator las kurang cermat } \\
\text { saat melakukan las }\end{array}$ & 112 & $\begin{array}{l}\text { Menyusun work instruction } \\
\text { agar pekerja dapat bekerja } \\
\text { dengan lebih terorganisir dan } \\
\text { melakukan pengawasan yang } \\
\text { lebih ketat }\end{array}$ \\
\hline $\begin{array}{l}\text { Ukuran } \\
\text { potong }\end{array}$ & $\begin{array}{l}\text { Plat tidak } \\
\text { dapat } \\
\text { digunakan }\end{array}$ & $\begin{array}{l}\text { Operator kurang teliti saat } \\
\text { melakukan proses potong plat }\end{array}$ & 168 & $\begin{array}{l}\text { Menyusun work instruction } \\
\text { agar pekerja dapat bekerja } \\
\text { dengan lebih terorganisir dan } \\
\text { melakukan pengawasan yang } \\
\text { lebih ketat }\end{array}$ \\
\hline \multirow[t]{2}{*}{ Defect ring } & $\begin{array}{l}\text { Proses } \\
\text { assembly } \\
\text { tidak dapat }\end{array}$ & $\begin{array}{l}\text { Tempat disimpannya } \\
\text { cetakan/model ring tidak } \\
\text { tertata dengan rapi }\end{array}$ & 240 & $\begin{array}{l}\text { Menata ulang tempat } \\
\text { penyimpanan cetakan/model } \\
\text { agar lebih tertata rapi }\end{array}$ \\
\hline & dilakukan & $\begin{array}{l}\text { Tidak ada pekerja yang } \\
\text { khusus membidangi QC dan } \\
\text { melakukan inspeksi }\end{array}$ & 64 & $\begin{array}{l}\text { Perusahaan membentuk } \\
\text { departemen QC atau } \\
\text { menambah pekerja yang } \\
\text { bertugas untuk melakukan } \\
\text { inspeksi produk sehingga } \\
\text { operator tidak harus } \\
\text { melakukan inspeksi }\end{array}$ \\
\hline Plat pecah & $\begin{array}{l}\text { Tutup akan } \\
\text { pecah saat } \\
\text { dilakukan } \\
\text { proses potong } \\
\text { dan kip tutup }\end{array}$ & $\begin{array}{l}\text { Perusahaan mencari harga } \\
\text { plat yang murah sehingga } \\
\text { plat yang didapatkan tidak } \\
\text { berkualitas standar }\end{array}$ & 120 & $\begin{array}{l}\text { Pihak perusahaan mencari } \\
\text { supplier lainnya yang mampu } \\
\text { menyediakan plat dengan } \\
\text { kualitas yang seragam dengan } \\
\text { harga yang sekompetitif } \\
\text { mungkin. }\end{array}$ \\
\hline $\begin{array}{l}\text { Ukuran } \\
\text { sarangan }\end{array}$ & $\begin{array}{l}\text { Suara yang } \\
\text { dihasilkan } \\
\text { knalpot } \\
\text { menjadi kasar }\end{array}$ & $\begin{array}{l}\text { Sisa plat hasil proses potong } \\
\text { diletakkan secara tidak rapi }\end{array}$ & 112 & $\begin{array}{l}\text { Menyediakan tempat khusus } \\
\text { bagi plat hasil sisa potong }\end{array}$ \\
\hline
\end{tabular}

prioritas utama untuk diperbaiki terlebih dahulu adalah defect kip tutup dengan total nilai RPN sebesar 476 kemudian diikuti oleh defect ring dengan nilai RPN 304, ukuran potong dengan nilai RPN 168, plat pecah dengan nilai RPN 120, dan yang terakhir adalah ukuran sarangan dengan nilai RPN sebesar 112. Sedangkan untuk prioritas pembenahan potential causes yang didapatkan melalui analisis RCA sebelumnya oleh PT Fajar Indah terlebih dahulu adalah tidak adanya jadwal untuk mengganti maupun membubut rol pada mesin kip, dimana potential cause ini memiliki nilai RPN sebesar 280 . 
Setelah mengetahui prioritas perbaikan yang harus dilakukan terlebih dahulu oleh pihak PT Fajar Indah, maka proses berikutnya yang harus dilakukan adalah menyusun usulan perbaikan untuk tiap potential causes yang dapat dilihat pada Tabel 11.

Berikut ini adalah penjelasan lebih lanjut mengenai usulan perbaikan yang dapat dipertimbangkan oleh PT Fajar Indah untuk memperbaiki proses produksi knalpot Colt Diesel FE 120 PS yang akan akan diurutkan berdasarkan prioritas nilai RPN hasil dari FMEA:

\section{Defect kip tutup}

Berdasarkan potential causes yang telah diketahui tersebut maka disusun usulan perbaikan dimana terdapat tiga usulan perbaikan yang dapat dipertimbangkan, yaitu yang pertama adalah melakukan penjadwalan maintenance untuk mengganti ataupun membubut rol mesin kip tutup. Sebagian besar defect kip tutup sendiri adalah tidak tertutup dengan rapatnya tutup knalpot dengan body knalpot yang disebabkan oleh rol mesin kip tutup telah mengalami aus. Rol mesin kip tutup baru akan dibubut setelah rol mengalami aus, hal ini sangat tidak efektif karena selain menyebabkan defect kip tutup juga menyebabkan downtime karena mesin akan berhenti beroperasi selagi rol dibubut. Oleh karena itu ada baiknya PT Fajar Indah untuk mulai menyusun jadwal maintenance mesin kip tutup untuk mengurangi defect kip tutup dan downtime mesin.

Usulan perbaikan yang kedua adalah menyusun work instruction bagi operator mesin potong dan operator las agar operator dapat menjalankan proses produksi dengan benar. Adakalanya operator tidak menjalankan proses produksi dengan baik dikarenakan kurang teliti atau cermat saat bekerja sehingga menyebabkan kesalahan seperti salah mengambil mal yang digunakan untuk memotong plat dan salah dalam menggunakan las. Penggunaan las tersebut berbeda-beda berdasarkan pada ketebalan plat yang digunakan. Oleh karena itu diperlukan work instruction agar operator dapat bekerja dengan baik dan benar menurut work instruction tersebut.

Sedangkan usulan perbaikan yang ketiga adalah melakukan pengawasan terhadap proses produksi yang lebih ketat. Work instruction yang nantinya disusun akan tidak memiliki arti apabila dalam prakteknya operator tidak menjalankan work instruction dengan benar dan sungguh. Maka dari itu diperlukan pula pengawasan yang lebih ketat selama proses produksi. Pengawasan yang lebih ketat ini diharapkan akan meminimalkan kesalahan yang dilakukan oleh operator selama proses produksi.

2. Ukuran potong

Potential cause pada defect ini yaitu operator mesin potong yang kurang teliti dan cermat saat melakukan proses pemotongan plat. Untuk mengurangi ketidaktelitian operator saat melakukan proses pemotongan plat maka diperlukan work instruction agar operator mesin potong dapat menjalankan tugasnya dengan benar. Selain itu diperlukan adanya pengawasan yang ketat agar work instruction nantinya dapat dilakukan dengan benar sehingga kesalahan operator dalam proses produksi dapat diminimalisasi.

\section{Defect ring}

Berdasarkan potential causes yang diketahui maka dapat disusun usulan perbaikan yang dapat dipertimbangkan oleh pihak perusahaan, yaitu yang pertama menata ulang tempat penyimpanan cetakan/model yang digunakan dalam proses mencetak ring agar tersimpan dengan lebih rapi. Cetakan/ model ring yang digunakan kebanyakan memiliki kemiripan model dengan beberapa model ring untuk knalpot kendaraan lainnya. Karena kemiripan model dan cetakan/model yang tidak memiliki label atau penamaan maka operator dapat salah mengambil model/cetakan ring. Oleh karena itu PT Fajar Indah sebaiknya mengatur kembali cara penyimpanan cetakan/model ring ini tidak hanya dibedakan menurut merek kendaraan namun juga dapat dilakukan pemberian label nama pada cetakan/model ring untuk menghindari kekeliruan dalam memilih 
cetakan/model ring yang akan digunakan dalam proses produksi.

Sedangkan usulan perbaikan lainnya adalah perusahaan membentuk departemen Quality Control (QC) atau melakukan penambahan pekerja yang bertugas untuk melakukan inspeksi sehingga operator tidak harus dibebani tanggung jawab untuk melakukan inspeksi produk. Selama ini PT Fajar Indah tidak memiliki departemen $\mathrm{QC}$ ataupun pekerja khusus yang bertugas untuk menangani inspeksi produk hasil proses produksi. Operator mesin sendirilah yang selama ini melakukan proses inspeksi produk. Hal ini dirasa cukup memberatkan operator karena operator sendiri telah terbebani dengan target produksi dari departemen produksi. Oleh karena itu, terkadang operator mesin tidak melakukan inspeksi dengan teliti sehingga menyebabkan lolosnya produk defect dimana produk defect ini baru terdeteksi saat dilakukan proses assembly akhir. Maka dari itu perusahaan sebaiknya melakukan penambahan pekerja yang bertugas khusus untuk melakukan inspeksi produk untuk mengurangi beban dari operator dan meminimalkan kemungkinan lolosnya produk defect ke proses produksi berikutnya.

4. Plat pecah

Potential cause plat pecah adalah dikarenakan perusahaan mencari plat dengan harga yang murah dimana hal ini menyebabkan plat yang didapatkan tidak selalu berkualitas standar yang sama. PT Fajar Indah melakukan hal tersebut dikarenakan dengan mencari plat yang berharga murah maka perusahaan dapat menghemat biaya hingga 20-25\% daripada jika membeli plat yang memiliki kualitas yang sama dan sesuai standar. Usulan perbaikan yang dapat dipertimbangkan oleh PT Fajar Indah adalah perusahaan mencari supplier bahan baku plat yang menyediakan plat dengan kualitas yang sama dan sesuai dengan standar dengan harga sekompetitif mungkin.

5. Ukuran sarangan

Berdasarkan hasil FMEA yang dilakukan diketahui bahwa potential cause yang menyebabkan defect pada ukuran sarangan adalah plat sisa hasil proses potong yang nantinya akan digunakan sebagai bahan baku pembuatan sarangan tidak memiliki tempat khusus sehingga operator proses pembuatan sarangan dapat melakukan kesalahan dalam mengambil plat. Selama ini plat sisa dari hasil proses pemotongan hanya diletakkan di lantai dan terkadang tercampur dengan ukuran plat yang berbeda-beda, hal inilah yang nantinya menyebabkan kesalahan operator proses sarangan dalam memilih plat yang akan digunakan sebagai bahan baku sarangan. Untuk mengatasi hal tersebut ada baiknya PT Fajar Indah menyediakan tempat khusus atau box sebagai tempat plat sisa hasil proses potong, dimana tempat khusus ini dapat dibedakan berdasarkan ketebalan platnya. Dengan adanya pembagian plat berdasarkan ketebalannya ini, maka kesalahan operator dalam memilih plat yang akan digunakan sebagai sarangan dapat dihindari.

\section{SIMPULAN}

Selama proses produksi knalpot terdapat lima CTQ atau jenis kecacatan yang terjadi, yaitu defect pada kip tutup, defect pada ring, defect ukuran sarangan, defect ukuran potong plat, dan yang terakhir defect karena plat mengalami pecah. Nilai sigma dan DPMO pada tahun 2013 sebesar 3,73 dan 12.879 menunjukkan bahwa PT Fajar Indah termasuk dalam kategori perusahaan yang sedang berkembang dan memiliki kemampuan untuk bersaing dengan perusahaan kompetitor lainnya. Sedangkan hasil penghitungan kapabilitas proses yang dilakukan menunjukkan hasil bahwa proses produksi masih perlu mendapatkan perbaikan lebih lanjut karena belum memenuhi nilai benchmark value yang biasanya digunakan oleh perusahaan lainnya. Terdapat beberapa usaha perbaikan yang dapat dilakukan oleh PT Fajar Indah antara lain adalah menyusun jadwal maintenance serta melakukan penataan ulang tempat penyimpanan cetakan/ model. 


\section{DAFTAR PUSTAKA}

Ardita, F.A. dan Sukardi, 2012. Analisis Pengurangan Jumlah Produk Cacat pada Industri Kertas dengan Pendekatan Lean Six Sigma, E-Jurnal Agroindustri Indonesia, 1(1), 38-44.

Burlikowska, M.D., 2011. Application of FMEA Method in Enterprise Focused on Quality, Journal of Achievement in Materials and Manufacturing Engineering, 45(1), 89-102.

Chakrabortty, R.K, Biswas, T.K., dan Ahmed, I., 2013. Reducing Process Variability by Using DMAIC Model: A Case Study in Bangladesh, International Journal for Quality Research, 7(1), 127-140.

Dewi, S.K. 2012. Minimasi Defect Produk dengan Konsep Six Sigma, Jurnal Teknik Industri, 13(1), $43-50$.

Gaspersz, V. 2007. Lean Six Sigma for Manufacturing and Service Industries, Jakarta: PT Gramedia Pustaka Utama.

Harsono, P.A. 2008. Metode Analisis Akar Masalah dan Solusi, Makara,Sosial Humaniora, 12(2), $72-81$.

Julien, D. dan Holmshaw, P. 2012. Six Sigma in a Low Volume and Complex Environment, International Journal of Lean Six Sigma, 3(10), 28-44.
Mentari, D.P. 2011. Pengendalian Mutu pada Proses Produksi Tuna Loin (Thunnus sp.) Menggunakan Metode Six Sigma, Tugas Sarjana, Departemen Teknologi Hasil Perairan Fakultas Perikanan dan Ilmu Kelautan Institut Pertanian Bogor.

Nee, L.S., Kamaruddin, S., Tien, C.W., dan Hamdan, A.N., 2012. Adoption of Six Sigma Concept in Process Improvements Methodology: A Case Study, International Journal of Emerging Technology and Advanced Engineering, 2(7), 12-17.

Ray, S. dan John, B., 2011. Lean Six-Sigma Application in Business Process Outsourced, International Journal of Lean Six Sigma, 2(4), 371-380.

Riandiani, R. 2010. Analisis Perbaikan Proses Produksi pada Proses Pembuatan Gitar Akustik dengan Pendekatan Lean Six Sigma dan Metode FMEA (Failure, Modes and Effects Analysis) di UKM. Sentana Art, Solo, Tugas Sarjana, Fakultas Teknologi Industri Institut Teknologi Sepuluh November.

Vanany, I. dan Emilasari, D. 2007. Aplikasi Six Sigma pada Produk Clear File di Perusahaan Stationary, Jurnal Teknik Industri, 9(1), 27-36. 